\title{
Does visual perceptual testing correlate with caregiver and teacher reported functional visual skill difficulties in school-aged children? Considerations for practice
}

Charlotte Sullivan

Department of Occupational Therapy, HSE South, Cork, Ireland

\author{
Helen Lynch
}

Department of Occupational Science and Occupational Therapy, University College Cork College of Medicine and Health, Cork, Ireland, and

\author{
Amanda Kirby \\ Dyscovery Centre, Faculty of Life Sciences and Education, \\ University of South Wales, Pontypridd, UK
}

\begin{abstract}
Purpose - As occupational therapists embrace evidence-informed and occupation-centred practice, the use of standardised visual perceptual tests remains a strong feature of typical paediatric practice. Yet, the research evidence for the use of such tools is inconclusive at best. This study compared the results of the Test of Visual Perceptual Skills (TVPS) with a checklist of reported functional difficulties in 30 children attending occupational therapy. The purpose of this paper was to determine the usefulness of visual perceptual testing in relation to occupation-centred practice.

Design/methodology/approach - A descriptive correlational study design was used. Participants were 30 primary school-age children who were on a paediatric occupational therapy caseload. An additional 30 typically developing children participated in the development of the checklist.

Findings - Correlations were found between reported functional visual skill difficulties and two subtests of the TVPS (visual memory and visual discrimination). No correlation was found between the reported functional difficulties and any of the other five subtests of the TVPS or the total score.

(C) Charlotte Sullivan, Helen Lynch and Amanda Kirby. Published in Irish Journal of Occupational Therapy. Published by Emerald Publishing Limited. This article is published under the Creative Commons Attribution (CC BY 4.0) licence. Anyone may reproduce, distribute, translate and create derivative works of this article (for both commercial and non-commercial purposes), subject to full attribution to the original publication and authors. The full terms of this licence may be seen at http://creativecommons.org/licences/by/4.0/legalcode

Declaration of conflicting interests: The authors confirm that there is no conflict of interests.

Funding: This research received no specific grant from any funding agency in the public, commercial or not-for-profit sectors.

Deirdre Cullen OT manager and Jan Wolstenholme for support during the study and during the preparation of this paper. Hazel Wolstenholme for assistance with the results section of the paper. Marie Thomas for supervision during the research study.
\end{abstract}

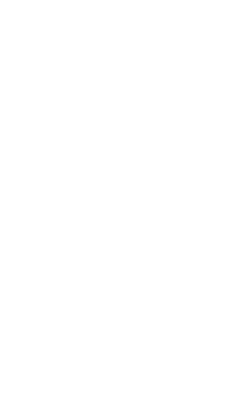


IJOT

46,2

Originality/value - Results highlight the weak relationship that existed in this study between standardised measures of visual perception, as measured by the TVPS, and functional difficulties. Therapists are cautioned to explore both the evidence base for continued use of standardised visual perceptual measures to inform occupation-centred practice and the need to embrace a more comprehensive person-centred approach to visual perceptual assessment.

Keywords Visual perception, Standardised testing, Children's occupational therapy

Paper type Research paper

\section{Introduction}

Occupational therapists recognise themselves as having unique skills in the area of visual perceptual assessment and intervention with children (Howard, 2002). It is therefore important that therapists practise from a sound theoretical base and use assessment tools that are fit for purpose (Rodger et al., 2005). To this end, therapists need to understand the entire visual system in relation to function, as well as the role of visual perception within this system, to be able to effectively address visual perceptual difficulties in children (Schneck, 2010, p. 349). Furthermore, occupational therapists need to be equipped to conduct a thorough assessment, so that they can link the child's occupational performance deficits to the correct foundational factors.

Over several decades, therapists' understanding of visual perception has been influenced by the descriptions of various visual perceptual components as described in certain standardised assessments (Lambert, 2011). One of the most widely used and influential assessments is the Test of Visual Perceptual Skills (TVPS), whose fourth edition (TVPS-4) has recently been published (Frauwirth, 2017). This describes seven discrete areas of visual perception which are assessed and scored separately. Therapists typically use this assessment to determine the areas of visual perception proving difficult for the child and plan remediation as guided by the manual. It is therefore critical that firstly we examine visual systems and visual perceptual theories to determine if this assessment has a strong theoretical basis, and, secondly, that we establish whether there is a link between the assessment results and the functional difficulties that children are actually experiencing.

This paper presents a research study that explored the relationship between visual perception, as measured by the TVPS-3 (prior to the publication of the TVPS-4), and functional abilities, as analysed through visual behaviour analysis, to explore the potential link between underlying performance components and areas of occupational performance among children of age 7 to 12 years. As the TVPS-4 remains largely unchanged in purpose or structure from previous editions (adding two lower-level test items and increasing the normed scores from 18 to 21 years), this research is still considered currently relevant to practicing therapists.

\section{Literature review}

For the purposes of this paper, the entire visual system refers to the eye, the neural pathways to the brain and the visual cortex of the brain. Scheiman (2011) outlines three key components related to the visual system:

(1) visual integrity, including eye health and visual acuity;

(2) visual efficiency skills, which includes ocular motor control, and how the two eyes work together; and

(3) visual information processing skills, or more narrowly, visual perception. 
Using this outline, he recommends the importance of a hierarchical approach to assessment and intervention addressing deficits at Parts 1 and 2 (visual integrity and efficiency) before intervening at Part 3 (visual perception) (Scheiman, 2011, p. 94).

Another influential model of visual perceptual abilities is presented within the Cattell Horn - Carroll (CHC) model of intelligence, where visual processing is described as "the ability to make use of simulated mental imagery (often in conjunction with currently perceived images) to solve problems" (Schneider and McGrew, 2012). Under this model 11 discrete skills are described which would generally fall under Scheiman's third component, Considerations for practice that of visual information processing skills.

Neural processing of vision has also been a focus of research, resulting in a hypothesis that visual perception consists of two main features: firstly the ability to perceive form to identify objects and discriminate them from their background (the 'what' pathway), and, secondly, the ability to perceive and judge space and distance (the 'where' pathway) (Milner and Goodale, 2008). Further studies have emphasised the interrelationship between these two pathways and report that adaptive goal-directed behaviour depends on the successful integration of the complementary contributions of both streams (James et al., 2003; Milner and Goodale, 2008).

Schneck (2010, p. 349) describes visual perception as a "dynamic blending of sensory information in which new visual and motor input are combined with previously stored data and then used to guide a reaction". Similar to Sheiman, Schneck highlights the importance of occupational therapists recognising the receptive functions of visual acuity and visual efficiency skills including oculomotor control, as well as the cognitive components of visual information processing. Also, in line with Milner and Goodale's (2008) hypothesis, Schneck (2010) describes two main types of visual perception (object perception and spatial perception) and highlights the importance of following a hierarchical model for assessment and intervention. To summarise, it is largely accepted that there are two main interrelated systems at play, that is object identification and spatial location, and that visual integrity, visual efficiency and visual cognitive processes should be addressed in a hierarchical manner for assessment and intervention.

The use of standardised visual perceptual tests as part of the assessment process in paediatric occupational therapy practice is well documented (Diamantis, 2006; Howard, 2002; Rodger, 2005). Clinical reasoning for the use of such assessments includes that they provide a concrete way of measuring the child's abilities pre- and post-intervention, they provide demonstrable outcomes for parents and professionals and they support clinical observations and diagnoses (Howard, 2002). One of the most widely used visual perceptual assessments internationally (Diamantis, 2006; Howard, 2002; Rodger et al., 2005) is the TVPS, recently published in a fourth edition, (TVPS-4) (Frauwirth, 2017).

The TVPS assessment, originally authored by Gardner (1996), was one of the few nonmotor visual perceptual tests available, which is an advantage when testing those with motor deficits. Since its development in the 1980s, it has been widely used for the purposes of diagnostic assessment, identification of progress and planning intervention (Martin, 2006). The TVPS-3 which was used for this study consists of 112 items grouped into seven subcomponents of visual perception: visual discrimination (VD), visual memory (VM), figure ground (FG), spatial relations (SRs), form constancy (FC), visual sequential memory (VSM) and visual closure (VC). With some minor changes to age bands and test items, the underlying purpose, format and administration of the TVPS remain the same for all editions.

The TVPS-3 has been shown to have strong test-retest reliability and inter-rater reliability (Martin, 2006, p. 50). However, one of the main criticisms of the TVPS is that of validity, and that no research-based rationale was presented in the manual for the particular construct of visual perception or the existence of the seven discrete areas of visual perception (Brown et al., 
IJOT

46,2

2003; Brown and Rodger, 2009). Chalfant and Scheffelin's (1969) comprehensive research review of central processing disorders and visual processing in children is cited as the source that guided the development of the TVPS (Martin, 2006). However, there is no explanation of how Gardner's seven discrete areas of visual perception in the TVPS are congruent with Chalfant and Scheffelin's theoretical work. In the TVPS-4 manual, Scheiman's (2011) model for information processing and the visual processing skills outlined in the CHC theory of cognitive abilities (Schneider and McGrew, 2012) is introduced as providing 'a clinically and educationally relevant context for understanding the skills assessed by the TVPS-4' (Frauwirth, 2017). In total, 3 of the 11 visual processing skills outlined in the CHC theory are purported to be measured by the TVPS-4, that is visualisation, flexibility of closure and VM. Although the updated theories presented in this manual are welcomed, there is still no explanation of how the TVPS subtests were developed, and how they are deemed to measure what they purport to measure. The importance of assessing the visual-receptive components involving the sensory and motor functions of the ocular system as well as assessing the visual cognitive components is highlighted in the manual, and this is also welcomed.

A number of studies have been carried out to determine the construct validity of these seven subtests. For example, Brown and Gabury (2006) correlated the results of the TVPS-R with the Developmental Test of Visual Motor Integration (VMI) (Beery et al., 2004), the Motor Free Visual Perceptual Test second edition (MVPT-2) (Colarusso and Hammill, 1996) and the Developmental Test of Visual Perception second edition (DTVP-2) (Hammill et al., 1993) on a cohort of 356 typically developing children. No correlation was identified between any of the individual subtests of the TVPS-R and any of the subtests of the other measures. In an item analysis, they found that some items appeared to have weak relationship with other items in four of the subscales. In another study, Coté (2011) carried out an external validity study of the VM subtest of the TVPS-3 by comparing it to a more naturalistic design-copy-frommemory task. Results showed only a weak correlation $(r=0.41)$. Coté concluded that the measures were not correlated strongly enough to add support to the validity of the VM subtest of the TVPS-3 as a test of the construct VM. In a further study with preschoolers in China, Chan and Chow (2005) explored the TVPS-R's criterion validity by correlating its results with the results of the MVPT-2. Results showed some evidence of validity providing only the total scores were used. No correlation with the MVPT-2 was found in the subtest areas of visual and sequential memory and weak-to-moderate correlation was found for all other areas. The authors concluded that test users should avoid using subtest and item scores when making clinical decisions or planning treatments and that research findings or treatment programmes based on the validity of subcategories of visual perception must be treated with great caution (Chan and Chow, 2005). To demonstrate construct validity in the TVPS- 4 manual, the results of the TVPS- 4 and MVPT- 4 administered to 32 participants were compared. The overall scores showed significant correlation; however, there were no individual subtest comparisons cited (Frauwirth, 2017, p. 59). Overall, it appears that the TVPS lacks adequate levels of construct and content validity, with uncertain conclusions drawn by the authors of these studies. On the one hand, the total score is identified as having some validity (Chan and Chow, 2005), whereas on the other hand, practitioners are advised not to use the overall perceptual quotient (Brown and Gabury, 2006). Some report that five of the seven subscales can be used with confidence while also reporting a lack of evidence of the existence of these discrete areas of visual perception (Brown and Gabury, 2006; Coté, 2011).

Therapists must be confident that the tests and measures they use to evaluate clients are assessing what they purport to do in a rigorous manner (Brown and Rodger, 2009) to be able to relate such findings to functional occupational performance (Weinstock-Zlotnick and Hinojosa, 2004). As "the relevance of visual perception to occupational performance is not 
well established" (Brown et al., 2003, p. 13), it is therefore imperative that a distinct relationship is found between the results of the TVPS and occupational performance deficits. Several studies have examined the relationship between the results of the TVPS-R for practice and various academic skills. For example, Richmond and Holland (2010) compared the results of the TVPS-R and the DTVP-2 with students' results in the areas of maths, spelling, dictation and comprehension in a sample of 173 students. They discovered no correlation with the results of the TVPS-R in any of these areas. However, they qualified that these results have to be interpreted with caution. Tseng and Chow (2000) examined the perceptual-motor processes of slow handwriters using the TVPS and other measures. VSM was the only subtest identified as being a predictor of handwriting speed, and only with 13.1 per cent of slow handwriters. Also Klein et al. (2011) used the TVPS-R to examine the relationships between visual perception scores and handwriting legibility and speed and found that the TVPS-R was a significant predictor of visual perceptual errors for far-point copying, accounting for 6 per cent of the variance. No correlation was found between TVPS-R results and handwriting speed, or between TVPS-R results and skilled or unskilled writers. The authors concluded that occupational therapists should be cautious in making inferences about the relationship between scores of visual perception and handwriting legibility and speed. No studies were found exploring the link between the results of the TVPS and any functional skills other than academics with children with developmental disorders identifying a significant gap in the research.

From the above discussion, it can be seen that there is weak evidence at best to determine a relationship between the results of the TVPS and functional skills. Despite the considerable body of research, it remains a controversial area with inconsistencies and inconclusive results (Brown et al., 2003; Coté, 2011). This is possibly because of the lack of consistency in terminology and assessment methods used for differently identified populations or the heterogeneous nature of the samples. It is also possibly because of the fact that the TVPS only addresses some of a range of identified visual processing skills (Frauwirth, 2017, p. 9) and that a broader assessment process is required to capture the visual skills difficulties that a child may be experiencing.

\section{Method}

The purpose of this study was to examine the relationship between standardised visual perceptual assessment results and the reported functional difficulties being experienced by children referred for occupational therapy using an occupational performance perspective. For the purpose of this study, reported functional difficulties refers to difficulties with the mastery of daily life activities that are typically associated with visual and visual perceptual skills (Lambert, 2011; Schneck, 2005). This research asked the following questions:

$R Q 1$. What is the relationship between the clinical sample's functional difficulties, as measured by a checklist of function, and the results of the TVPS-3?

$R Q 2$. What implications will the findings have for clinical practice?

Ethical approval was granted in 2012 by the Clinical Research Ethics Committee of the Cork Teaching Hospitals, Ireland, identifying information removed for review.

A descriptive, correlational research design was used to determine whether there is a relationship between the results of the TVPS-3 and the functional difficulties the children are experiencing as described by a checklist of function: the Children's Visual Behaviour Checklist (CVBC). This checklist was developed for the study as outlined below. The checklist was administered to both typically developing children and children attending community 
IJOT

46,2

occupational therapy to explore its effectiveness at capturing children's functional visual difficulties.

\section{Participants}

Participants comprised two groups of children: typically developing children and children referred to occupational therapy because of functional difficulties. A convenience sample was drawn from two local primary schools in a rural area of Munster, Ireland, for the typically developing sample and from children enrolled in a community paediatric occupational therapy (CPOT) service for the clinical sample.

The inclusion criteria for both groups of children were as follows:

- aged between 7 years and 12 years, 11 months of age;

- attending mainstream primary school; and

- without a diagnosed neurological or intellectual disability, or uncorrected visual or hearing loss.

Additionally, the typically developing sample had to be of average range academically in reading and maths as measured by the Mary Immaculate Reading Attainment Test and the Standardised Irish Graded Mathematics Attainment Test (Wall and Burke, 2004a,b), and the clinical sample had to be presenting with reported functional occupational difficulties.

Following active recruitment process through distribution of information leaflets, informed consent was given by eligible families for their children to take part. Informed assent was also gained from the children. A final sample of 30 children was recruited from the CPOT enrolment: the clinical sample. Additionally, the typically developing sample of 30 children from local schools was purposefully selected from the families who accepted the invitation to participate, to match the clinical sample by age and gender. The typically developing sample was coded by the teachers to preserve the participants' anonymity. There were no dropouts from either sample.

\section{Instruments}

For this study, it was necessary to use a tool that could identify the children's functional difficulties across all areas of occupational performance. No existing tools were found to be entirely suitable for this project; therefore, the CVBC was developed. Guided by Rosenblum (2008), three stages were implemented to develop the checklist. The construction of the tool began in Stage 1, with the identification of multiple behaviours typically attributed to visual perception. This list was compiled with reference to existing unpublished checklists and questionnaires in circulation including online checklists (Lambert, 2011), and from the expert opinion of a core research advisory group consisting of six experienced paediatric occupational therapists. In Stage 2, further consultation was carried out with 19 experienced occupational therapists and 1 behavioural ophthalmologist across Ireland, the UK and the USA, who were asked to evaluate whether in their experience the items adequately addressed the range of visual perceptual behaviours covering all areas of occupational performance. The Stage 3 involved trialling the tool for ease of use with five parents and teachers of children attending occupational therapy and five parents and teachers of typically developing children. The results of the trial indicated that the questionnaire was easy to use and that it clearly differentiated between the typically developing and clinical populations. Finally, members of the core research advisory group compiled subsets of questions from the $\mathrm{CVBC}$ that best described the functional difficulties that clinicians most 
typically attribute to the various areas of visual perception as described by the TVPS. Only questions that all members agreed on were included in the subsets.

The CVBC was finalised as a checklist style questionnaire with 50 items, divided into parent's and teacher's sections. Parents reported on the areas of self-care and play/leisure, and teachers reported on productivity, which was further broken down into general school skills, reading, maths and writing skills. Space was provided for additional comments. Each item on the checklist was scored as follows: Not like my child: 0, Sometimes like my child: 1 , Often like my child: 2, Always like my child: 3 . The checklist is included as an Appendix at the end of the paper. The effectiveness of the checklist to identify children with functional visual skills difficulties was explored by comparing the results of the clinical sample with the typically developing sample as described in the Results section.

The TVPS third edition (TVPS-3) (Martin, 2006) as described in the literature review was chosen for this study because it was the most frequently purchased TVPS on the Irish market (ETC, 2012, personal communication) and one of the most widely used assessments internationally (Rodger et al., 2005; Payne, 2002; Howard, 2002). Therefore, any findings from this study may be considered to have relevance both in Ireland and internationally to contribute to current occupational therapy practice knowledge in this area.

\section{Procedures}

Data collection for this project involved administering the CVBC to all 60 participants' parents and teachers, and comparing the results from the typically developing sample with the results from the clinical sample to determine the effectiveness of the CVBC in identifying children with functional difficulties. The typically developing sample's parents and teachers completed the CVBC through the school, and the coded questionnaires were returned to the researcher to preserve anonymity. The clinical sample's parents completed the CVBC at a clinic appointment, and it was then sent to the child's teacher to be completed.

To compare the results of the TVPS- 3 with the results of the CVBC, the TVPS- 3 was administered to the 30 children in the clinical sample only, at the same clinic appointment mentioned above, and the results were correlated with the results of the CVBC for the clinical sample of children attending CPOT.

\section{Data analysis}

Data were analysed using Statistical Package for the Social Sciences version 21 (SPSS). Firstly, an independent two group $t$-test was used to examine the differences in the results of the CVBC between the clinical sample and the typically developing sample. Two-way analysis of variances (ANOVAs) were also used to explore the impact of age and group on individual areas of occupational performance. Frequency statistics were used to establish cut-off scores.

Secondly, descriptive statistics were used to identify what proportion of the clinical sample scored as having significant difficulty on the TVPS-3 and on the CVBC. Independent samples $t$-test was used to compare the results of the CVBC between the children that scored below average in the TVPS-3 and those that scored in the average range. Pearson's correlations were conducted to compare the results of the subtests of the TVPS-3 and corresponding subsets of the CVBC in the clinical sample.

\section{Results \\ Difference in the results of the Children's Visual Behaviour Checklist between the typically developing sample and the clinical sample}

An independent samples t-test was conducted to compare the CVBC scores for the clinical sample and typically developing sample. The results showed a significant difference in
Considerations for practice 
IJOT

46,2

96

scores between the two groups for each of the 50 questions of the CVBC $(p<0.01$ for all but one question; Q22 'Has difficulty finding way around school or unfamiliar environments' $p<0.05)$. This suggests that the checklist is effective at discriminating between children who have been identified as having functional difficulties, and have thereby been referred to occupational therapy, and those who have not.

A series of two-way between-groups ANOVA were conducted to explore the impact of age (7-8-, 9-10- and 11-12-year-olds) and group (clinical sample or typically developing sample) on the individual areas of occupational performance addressed by the CVBC to confirm that it is a robust measure to use for all areas of occupational performance. There was a statistically significant main effect for group (clinical sample and typically developing sample) across all areas of occupational performance. There was no statistically significant main effect for age. These results demonstrate that the CVBC is effective in discriminating between a clinical cohort and a typically developing cohort in all areas of occupational performance across all applicable age ranges (i.e. age: 7-12 years) as illustrated in Table I.

\section{Relationship between the Test of Visual Perceptual Skills-Third Edition results and the Children's Visual Behaviour Checklist results within the clinical sample}

The relationships between the clinical sample's functional difficulties as measured by the CVBC and the results of the TVPS-3 were explored, and the proportion of the clinical sample with low scores on the TVPS-3 was investigated. It was discovered that even though a total of 28 of the clinical sample were identified as having significant functional visual skill difficulties using the CVBC, only 12 of the clinical sample scored below the average range in the TVPS-3.

The clinical sample was then divided into two groups; those whose TVPS-3 scores were below the average range $(n=12)$, and those whose scores were within the average range $(n=18)$. An independent samples $t$-test was used to establish whether there were any significant differences in CVBC scores for these two groups across all areas of occupational performance.

Table II illustrates that even though the children with identified VP difficulty according to the TVPS-3 scored higher on the CVBC in all areas, none of the differences were large enough to be significant.

The relationships between the clinical sample's functional difficulties as measured by the CVBC and the results of the TVPS-3 were further explored as follows. The TVPS-3 subtest results were correlated with the corresponding subsets of items of the CVBC (as described earlier) using Pearson product-moment correlation coefficient and are presented in Table III.

\section{Table I.}

Two-way ANOVA illustrating significant main effect for group (clinical sample and typically developing sample) and no significant main effect for age (7-8-, 910-, 11-12-year-olds) Area of occupational performance Group $F$ value Group significance Age $F$ value Age significance

\begin{tabular}{lrlll}
\hline Self-care & 82.11 & $p<0.01$ & 0.38 & 0.68 \\
Play/leisure & 68.20 & $p<0.01$ & 0.28 & 0.75 \\
General school skills & 45.65 & $p<0.01$ & 0.43 & 0.65 \\
Reading skills & 39.11 & $p<0.01$ & 0.74 & 0.48 \\
Maths skills & 61.09 & $p<0.01$ & 0.57 & 0.57 \\
Writing skills & 149.18 & $p<0.01$ & 0.45 & 0.64 \\
Total parent reported & 90.43 & $p<0.01$ & 0.39 & 0.68 \\
Total teacher reported & 118.53 & $p<0.01$ & 0.27 & 0.76 \\
\hline
\end{tabular}




\begin{tabular}{|c|c|c|c|c|c|}
\hline $\begin{array}{l}\text { CVBC area of } \\
\text { occupational performance }\end{array}$ & $\begin{array}{l}\text { TVPS-3 identification of } \\
\text { VP difficulty }\end{array}$ & $\begin{array}{l}\text { Mean CVBC } \\
\text { scores }\end{array}$ & SD & $\begin{array}{l}\text { Significance } \\
\text { (two-tailed) }\end{array}$ & $\begin{array}{l}\text { Considerations } \\
\text { for practice }\end{array}$ \\
\hline \multirow[t]{2}{*}{ Self-care } & Identified difficulty & 16.50 & 8.085 & 0.073 & \\
\hline & No identified difficulty & 11.78 & 5.847 & & \\
\hline \multirow[t]{2}{*}{ Play/leisure } & Identified difficulty & 11.17 & 7.469 & 0.452 & \\
\hline & No identified difficulty & 9.33 & 4.270 & & \\
\hline \multirow[t]{2}{*}{ General school skills } & Identified difficulty & 9.08 & 4.926 & 0.395 & 97 \\
\hline & No identified difficulty & 7.44 & 5.193 & & \\
\hline \multirow[t]{2}{*}{ Reading skills } & Identified difficulty & 6.42 & 4.420 & 0.611 & \\
\hline & No identified difficulty & 5.56 & 4.540 & & \\
\hline Maths skills & Identified difficulty & 9.67 & 3.962 & 0.079 & \\
\hline \multirow{2}{*}{ Writing skills } & $\begin{array}{l}\text { No identified difficulty } \\
\text { Identified difficulty }\end{array}$ & $\begin{array}{r}6.89 \\
21.25\end{array}$ & $\begin{array}{l}4.171 \\
5.011\end{array}$ & 0.080 & \\
\hline & No identified difficulty & 16.83 & 7.334 & & \\
\hline \multirow[t]{2}{*}{ Parent report } & Identified difficulty & 27.67 & 14.883 & 0.188 & Table II. \\
\hline & No identified difficulty & 21.11 & 8.710 & $010-$ & CVBC scores for \\
\hline Teacher report & $\begin{array}{l}\text { Identified difficulty } \\
\text { No identified difficulty }\end{array}$ & $\begin{array}{l}46.42 \\
36.72\end{array}$ & $\begin{array}{l}13.534 \\
16.725\end{array}$ & \multirow{3}{*}{0.089} & those with and \\
\hline \multirow[t]{2}{*}{ CVBC overall total } & Identified difficulty & 74.08 & 26.366 & & without identified \\
\hline & No identified difficulty & 57.83 & 23.662 & & difficulty on TVPS-3 \\
\hline $\begin{array}{l}\text { TVPS- } 3 \text { area of VP and } \\
\text { corresponding CVBC subset }\end{array}$ & Pearson correlation & Significance & $\begin{array}{l}\text { Coefficient of } \\
\text { determination }\end{array}$ & $\begin{array}{l}(\%) \text { of shared } \\
\text { variance }\end{array}$ & \\
\hline VD & -0.394 & $0.031 *$ & 0.155 & 15.5 & \\
\hline VM & -0.522 & $0.003 * *$ & 0.272 & 27.2 & \\
\hline Visual SRs & -0.237 & 0.208 & 0.056 & 5.6 & Table III. \\
\hline Visual FC & -0.204 & 0.279 & 0.042 & 4.2 & The correlations \\
\hline VSM & -0.328 & 0.076 & 0.107 & 10.7 & between subtest \\
\hline Visual FG & -0.305 & 0.102 & 0.093 & 9.3 & resilts of the TVPS \\
\hline $\mathrm{VC}$ & -0.358 & 0.052 & 0.128 & 12.8 & results of the IVPS \\
\hline \multicolumn{5}{|c|}{$\begin{array}{l}\text { Notes: *Correlation is significant at the } 0.05 \text { level (two-tailed); }{ }^{* *} \text { correlation is significant at the } 0.01 \text { level } \\
\text { (two-tailed) }\end{array}$} & $\begin{array}{l}\text { corresponding } \\
\text { subsets of the CVBC }\end{array}$ \\
\hline
\end{tabular}

It can be seen from this analysis that there is a weak correlation between the CVBC VD subset and the TVPS-3 VD subtest $(p<0.05)$, and there is a stronger correlation between the CVBC VM subset and the TVPS-3 VM subtest $(p<0.01)$. However, there is no correlation between the CVBC subsets and the TVPS-3 subtests for any of the other areas. As illustrated in the table above, even in the two items that have a statistically significant correlation, they only share 15 per cent or 27 per cent of their variance, which in a sample of this size implies that clinically, this relationship should be interpreted cautiously.

\section{Discussion}

The results of the above study confirm what was identified in other studies: that there is very little evidence of a link between functional performance and the results of the TVPS (Brown et al., 2003; Richmond and Holland, 2010). When analysing the relationship between the CVBC and the TVPS-3, there was a tenuous relationship at best between the results of the TVPS-3 and the functional difficulties being experienced by the children referred to 
CPOT. Over half of the clinical sample who had been identified by the CVBC as having significant difficulty with functional visual skills was not identified by the TVPS-3 as having a significant degree of difficulty with visual perception. When test validity is taken into consideration, therapists would expect to use tools such as the TVPS-3 to identify which children in a clinical sample are more likely to have poor functional visual perception, and then relate this information to providing guidance or planning support. However, as test validity has been shown to be the most criticised aspect of the TVPS (Brown and Gabury, 2006; Chan and Chow, 2005; Coté, 2011), therapists need to be cautious when interpreting the results. Although the CVBC is not purported to be a replacement for tests such as the TVPS, it has the potential to be valuable as part of a holistic assessment process to gain important insight into the nature and extent of the functional visual skill difficulties being experienced by children. Further development of the checklist to improve its reliability and validity is required; however, the preliminary findings, particularly how effective the checklist is at discriminating between the typically developing population and the clinical group are promising.

When using standardised measures of visual perception, it is important that therapists realise the limitations of these measures. As stated in the TVPS-4 manual, this assessment is only addressing a limited range of recognised visual processing abilities (3 of 11 defined abilities) (Schneider and McGrew, 2012, Frauwirth, 2017). As also outlined in the manual, there is evidence of validity in terms of a positive relationship with age and with learning disabilities. Therefore, this assessment could be useful to determine whether a child has deficits within a narrow range of visual-cognitive areas and whether the child is completing the given tasks as would be expected given their age and cognitive ability. This type of analytical assessment practice could be viewed as being of limited practical application for occupational therapists when determining the underlying causes of a child's functional difficulties.

As outlined in the literature review, an understanding of visual perceptual processes is key for therapists to make critically important decisions about the clinical utility of various assessment and intervention options. Although the TVPS is recognised to capture several of the visual perceptual cognitive abilities outlined in the CHC theory (Schneider and McGrew, 2012), there is no evidence to support the existence of the seven discrete areas of visual perception either in the manual of the TVPS- 4 or in other literature. It is therefore important that if therapists do use assessments such as these to gain some understanding of an individual's visual processing abilities, they are cognisant of the fact that they are advised not to use individual subtest results to draw conclusions or plan interventions. (Brown and Gabury, 2006; Chan and Chow, 2005). In clinical situations where children are identified by the TVPS as having specific difficulty with, for example, 'figure ground' or 'visual closure', in reality they may be having difficulty with visual attention or language comprehension.

Despite the fact that visual perceptual processes have been identified as having two main neural streams, that of object identification and spatial perception (Milner and Goodale, 2008), no standardised assessment of visual perception for children exists that has managed to create subtests that load on these factors. In the absence of such a tool, therapists need to consider their options and the information available to them that they can rely on. For sound clinical reasoning and evidence-based analysis of visual perceptual impairments to be possible, a more in-depth, informed assessment process of the entire visual system, including eye health, visual efficiency and visual processing ability should be conducted (Scheiman, 2011, p. 94; Schneck, 2010, p. 377),

\section{Implications}

Visual perception has been identified as an area that does impact on function (Klein et al., 2011; Schneck, 2010), and one that occupational therapists identify with as a unique area of 
practice (Howard, 2002). However, information from the literature suggests that a significant change in practice is necessary. This is in line with the general trend in occupational therapy towards a more occupation focused approach (Case-Smith, 2015, p. 22; Diamantis, 2006). Indeed the emphasis on addressing occupational performance skills is now highlighted in both standardised and non-standardised assessments (Diamantis, 2006; Payne, 2002). Occupational therapists need an improved understanding of visual perception and the entire visual system in the context of developmental and acquisitional theories (Schneck, 2010, p. 352). The assessment process for visual perception has to be married into the entire for practice assessment process for the child, where the use of any specific standardised assessments is used with caution as advised in the literature. Consideration must also be given to the time it takes and the associated cost of delivering the TVPS or similar assessments as part of the assessment process. As with any area of assessment, thorough information gathering and triangulation of information from multiple sources are essential, and with further development, the CVBC could be a useful occupation focused tool in this regard. Careful clinical observations of the child carrying out relevant activities of daily living have been highlighted as essential in the assessment process (Schneck, 2005, p. 429). The importance of and reasons for the use of standardised assessments have been highlighted earlier in this paper. If occupational therapists are compelled to use standardised measures for the reasons stated, there are several alternatives that may be more fit for purpose and more in line with occupational therapy models of practice than the traditionally used visual perceptual assessments. Guided by frameworks such as the International Classification of Functioning (World Health Organisation, 2002), functional tools such as the School AMPS (Fisher et al., 2007), the Miller Function and Participation Scale (M-Fun) (Miller, 2006) and the GoalOriented Assessment of Lifeskills (GOAL) (Miller et al., 2013) could be considered. Both the M-Fun and GOAL assessment manuals highlight the importance of the visual system for function and discuss the neurological foundations of visual perception and visual motor integration with reference to the test items, and much information can be gleaned from the qualitative observations carried out during their administration. Therapists need to be able to answer the 'what' question pertaining to the functional difficulties and the 'why' question pertaining to the foundational factors to plan successful interventions.

\section{Limitations}

Limitations of this study include the fact that the convenience sample recruited was limited to one local area known to the researcher and was drawn from a predominantly rural population. The results may therefore not be generalisable to the wider population. Also, there is an assumption that the CVBC is measuring predominantly visual skills, and although every effort was made to ensure this, there may be other reasons for any of the observed difficulties. Another potential limitation is the possibility of dual bias in the CVBC, where the respondents for the clinical sample may over-report because of a heightened awareness of their child's difficulties, and the respondents for the typically developing sample may underreport. A further limitation of this study is that the sample size may have been too small to detect an effect, and that future research should replicate this study with a larger sample size.

\section{Conclusion}

This paper highlights that there is a weak, if any, meaningful relationship between the overall results of the TVPS and difficulties in functional daily living skills, as demonstrated in the literature reviewed and by the results of this study. There is also a lack of evidence to support that the TVPS measures seven discrete areas of visual perception that relate to functional difficulties, and results remain inconclusive on the contribution of the subtests in 
analysing actual functional visual perceptual difficulties. A lack of consistency between assessment tools used and theory and practice models referred to in occupational therapy is therefore worthy of note.

In conclusion, occupational therapists need to be better informed regarding the current evidence base and theoretical models pertaining to visual perception. They need to reflect on current common practice and embrace changes to a more occupation focused assessment to ultimately improve outcomes for clients. Further research is needed to untangle the relationships between visual processing difficulties and function, so that more robust visual perception tools can be designed to support assessment and provide ways for more effective occupation-centred practice.

\section{References}

Beery, K., Buktenica, N. and Beery, N. (2004), The Beery-Buktenica Developmental Test of Visual Motor Integration Administration, Scoring and Teaching Manual, 5th ed., Pearson Education, San Antonio

Brown, T. and Gabury, I. (2006), "The measurement properties and factor structure of the test of visual perceptual skills - revised: implications for occupational therapy assessment and practice", American Journal of Occupational Therapy, Vol. 60 No. 2, pp. 182-193.

Brown, T. and Rodger, S. (2009), "An evaluation of the validity of the test of visual perceptual skills revised using the rasch measurement model", British Journal of Occupational Therapy, Vol. 72 No. 2, pp. 65-78.

Brown, T., Rodger, S. and Davis, A. (2003), "Test of visual perceptual skills - revised: an overview and critique", Scandinavian Journal of Occupational Therapy, Vol. 10 No. 1, pp. 3-15.

Case-Smith, J. (2015), “An overview of occupational therapy for children”, in Case-Smith, J. and Clifford O'Brien, J. (Eds), Occupational Therapy for Children and Adolescents, 7th ed., Mosby, MO, p. 22.

Chalfant, J. and Scheffelin, M. (1969), Central Processing Disorders in Children: A Review of the Research, Department of Health, Education and Welfare, Bethesda.

Chan, P. and Chow, S. (2005), "Reliability and validity of the test of visual perceptual skills (nonmotor), - revised for Chinese pre-schoolers", American Journal of Occupational Therapy, Vol. 59 No. 4, pp. 369-376.

Colarusso, R. and Hammill, D. (1996), Motor-Free Visual Perception Test-Revised, Academic Therapy Publications, Novato.

Coté, C. (2011), "An external validity study of the visual memory subtest of the test of visual perceptual skills, third edition”, British Journal of Occupational Therapy, Vol. 74 No. 10, pp. 484-488.

Diamantis, A. (2006), "Use of standardised tests in paediatrics: the practice of private occupational therapists working in the United Kingdom", British Journal of Occupational Therapy, Vol. 69 No. 6, pp. 281-287.

Fisher, A.G., Bryze, K., Hume, V. and Griswold, L.A. (2007), School AMPS: School Version of the Assessment of Motor and Process Skills, 2nd ed., Three Star Press, Fort Collins, CO.

Frauwirth, S. (2017), Test of Visual Perceptual Skills, 4th ed., Academic Therapy Publications, Novato.

Gardner, M. (1996), Test of Visual Perceptual Skills (Non-Motor),- Revised, Academic Therapy Publications, Novato.

Hammill, D., Pearson, N. and Voress, J. (1993), Developmental Test of Visual Perception, 2nd ed., Pro-Ed, TX.

Howard, L. (2002), "A survey of paediatric occupational therapists in the United Kingdom", Occupational Therapy International, Vol. 9 No. 4, pp. 326-343.

James, T.W., Culham, J., Humphrey, G.K., Milner, A.D. and Goodale, M.A. (2003), "Ventral occipital lesions impair object recognition but not object-directed grasping: an fMRI study", Brain, Vol. 126 No. 11, pp. 2463-2475. 
Klein, S., Guiltner, V., Sollereder, P. and Ciu, Y. (2011), "Relationships between fine-motor, visual motor and visual perception scores and handwriting legibility and speed", Physical \& Occupational Therapy in Pediatrics, Vol. 31 No. 1, pp. 103-114.

Lambert, M. (2011), "Checklist for identifying visual perception difficulties in a student's schoolwork", available at: http://therapyinyourhome.net/docs/Visual_perception_check_list.pdf (accessed 29 July 2013).

Martin, N. (2006), Test of Visual Perceptual Skills, 3rd ed., Academic Therapy Publications, CA.

Miller, L.J. (2006), Miller Function and Participation Scales: Examiner's Manual, PsychCorp Harcourt Assessment, San Antonio, TX.

Miller, L.J., Oakland, T. and Herzberg, D. (2013), Goal-Oriented Assessment of Lifeskills (GOAL), Western Psychological Services, Torrance, CA.

Milner, A.D. and Goodale, M.A. (2008), "Two visual systems re-viewed”, Neuropsychologia, Vol. 46 No. 3, pp. 74-785.

Payne, S. (2002), "Standardised tests: an appropriate way to measure the outcome of paediatric occupational therapy", British Journal of Occupational Therapy, Vol. 65 No. 3, pp. 117-122.

Richmond, J. and Holland, K. (2010), "The relationship between a teacher checklist and standardised tests for visual perception skills: a South African remedial primary school perspective", South African Journal of Occupational Therapy, Vol. 40 No. 3, pp. 9-16.

Rodger, S., Brown, T. and Brown, A. (2005), "Profile of paediatric occupational therapy practice in Australia”, Australian Occupational Therapy Journal, Vol. 52 No. 4, pp. 311-325.

Rosenblum, S. (2008), "Development, reliability and validity of the handwriting proficiency screening questionnaire (HPSQ)", The American Journal of Occupational Therapy : Official Publication of the American Occupational Therapy Association, Vol. 62 No. 3, pp. 298-307.

Scheiman, M. (2011), Understanding and Managing Vision Deficits: A Guide for Occupational Therapists, 3rd ed., Slack Incorporated, NJ.

Schneck, C. (2005), "Visual perception", in Case-Smith, J. (Ed.), Occupational Therapy for Children, 5th ed., Mosby, MO, pp. 412-448.

Schneck, C. (2010), “A frame of reference for visual perception”, in Kramer, P. and Hinojosa, J. (Eds), Frames of Reference for Pediatric Occupational Therapy, 3rd ed., Lippincott, Williams and Wilkins, MD, p. 349.

Schneider, W. and McGrew, K. (2012), "The Cattell-Horn-Carroll model of intelligence", in Flanagan, D. and Harrison, P. (Eds), Contemporary Intellectual Assessment: Theories, Tests and Issues, 3rd ed., Guildford Press, New York, NY, pp. 99-144.

Tseng, M. and Chow, S. (2000), "Perceptual motor function of school-aged children with slow handwriting speed", American Journal of Occupational Therapy, Vol. 54 No. 1, pp. 83-88.

Wall, E. and Burke, K. (2004a), Mary Immaculate Reading Attainment Test (MICRA-T), CJ Fallon, Dublin.

Wall, E. and Burke, K. (2004b), Standardised Irish Graded Mathematics Attainment Test (SIGMA-T), CJ Fallon, Dublin.

Weinstock-Zlotnick, G. and Hinojosa, J. (2004), "Bottom-up or top-down evaluation: is one better than the other?", The American Journal of Occupational Therapy : Official Publication of the American Occupational Therapy Association, Vol. 58 No. 5, pp. 594-599.

World Health Organisation (2002), Towards a Common Language for Functioning, Disability and Health, ICF, WHO, Geneva.

\section{Further reading}

IBM Corporation (2012), IBM SPSS Statistics for Windows, Version 21.0, IBM Corp, Armonk.

Milner, A. and Goodale, M. (2006), The Visual Brain in Action, 2nd ed., Oxford University Press, New York, NY. 


\section{Children's Visual Behaviour Checklist}

\section{Age $7-12$ years}

Name / Code:

Class:

Has your child ever had an eye test (at school or otherwise?) Yes

Has your child got a history of a squint, lazy eye or any other uncorrected visual problem?

Yes $\square$ No $\square$ Please give details:

Does your child wear glasses? Yes $\square$ No the board etc):
Date of Birth:

Male Female

Does your child have any diagnosed difficulties? (such as Dyspraxia (DCD), ADHD / ADD, Specific Language Disorder, Dyslexia, ASD, Other):

Yes

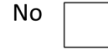

If yes, please specify:

\section{Instructions}

There are two parts to this checklist.

The first part is for parents or primary caregivers to complete, and covers skills to do with self-care and play / leisure activities.

The second part is for teachers to complete and covers skills related to the school environment.

Use the following key to complete the checklist:

Not like my child: The statement does not describe my child / pupil at all. Sometimes like my child: The statement describes what my child / pupil is like at times.

Often like my child: The statement describes what my child is frequently like. Always like my child: The statement typically describes my child / pupil.

NB: It is very important that all items are completed to gain a valid score for the child. Please call on if you are unclear about how to answer a question. If it is really not possible to rate a particular item, please write 'Don't Know' across the boxes. 
Parent / caregiver Section 1 (Page 2):

\begin{tabular}{|c|c|c|c|c|}
\hline $\begin{array}{l}\text { Please check the box that best describes your child } \\
\text { when compared to other children the same age }\end{array}$ & $\begin{array}{l}\text { Not like } \\
\text { my child }\end{array}$ & $\begin{array}{l}\text { Sometimes } \\
\text { like my child }\end{array}$ & $\begin{array}{l}\text { Often like } \\
\text { my child }\end{array}$ & $\begin{array}{l}\text { Always like } \\
\text { my child }\end{array}$ \\
\hline \multicolumn{5}{|l|}{ Self-Care skills: } \\
\hline \multicolumn{5}{|l|}{ 1. Tends to put clothes on back to front } \\
\hline \multicolumn{5}{|l|}{$\begin{array}{l}\text { 2. Has trouble lining up buttons and button } \\
\text { holes correctly }\end{array}$} \\
\hline \multicolumn{5}{|l|}{$\begin{array}{l}\text { 3. Has difficulty telling which shoe goes on } \\
\text { which foot }\end{array}$} \\
\hline \multicolumn{5}{|l|}{ 4. Has difficulty setting the table correctly } \\
\hline \multicolumn{5}{|l|}{$\begin{array}{l}\text { 5. Has difficulty judging amounts when helping } \\
\text { self to food or drink }\end{array}$} \\
\hline \multicolumn{5}{|l|}{$\begin{array}{l}\text { 6. Tends to bang into or trip over things more } \\
\text { than others }\end{array}$} \\
\hline \multicolumn{5}{|l|}{$\begin{array}{l}\text { 7. Has difficulty finding objects that are in a } \\
\text { cluttered drawer }\end{array}$} \\
\hline \multicolumn{5}{|l|}{$\begin{array}{l}\text { 8. Has / had difficulty learning to use a clock- } \\
\text { face to tell the time }\end{array}$} \\
\hline \multicolumn{5}{|l|}{ 9. Confuses left and right } \\
\hline \multicolumn{5}{|l|}{$\begin{array}{l}\text { 10. Tends to place things e.g. a drink, too near } \\
\text { the edge of the table }\end{array}$} \\
\hline \multicolumn{5}{|l|}{$\begin{array}{l}\text { 11. Cannot find shoes or other belongings in a } \\
\text { visually cluttered room }\end{array}$} \\
\hline \multicolumn{5}{|l|}{ 12. Hesitates going up or down curbs / steps } \\
\hline \multicolumn{5}{|l|}{ Play / leisure: } \\
\hline \multicolumn{5}{|l|}{ 13. Tends not to read for pleasure } \\
\hline \multicolumn{5}{|l|}{ 14. Avoids art / craft / painting activities } \\
\hline \multicolumn{5}{|l|}{$\begin{array}{l}\text { 15. Has difficulty judging distance when playing } \\
\text { ball games }\end{array}$} \\
\hline \multicolumn{5}{|l|}{$\begin{array}{l}\text { 16. Has difficulty following directional } \\
\text { commands in games e.g. in sports training / } \\
\text { rounders / dancing etc. }\end{array}$} \\
\hline \multicolumn{5}{|l|}{$\begin{array}{l}\text { 17. Has difficulty making models from visual } \\
\text { instructions i.e. Lego kits, jewellery making }\end{array}$} \\
\hline \multicolumn{5}{|l|}{$\begin{array}{l}\text { 18. Has more difficulty than friends / siblings at } \\
\text { playing typical computer / video games }\end{array}$} \\
\hline \multicolumn{5}{|l|}{ 19. Avoids jigsaws (or avoided when younger) } \\
\hline \multicolumn{5}{|l|}{$\begin{array}{l}\text { 20. Generally avoids construction toys such as } \\
\text { Knex, Lego or Meccano }\end{array}$} \\
\hline \multicolumn{5}{|l|}{$\begin{array}{l}\text { 21. Has difficulty with games such as word } \\
\text { searches or spot the difference etc. }\end{array}$} \\
\hline $\begin{array}{l}\text { For Office Use Only } \\
\text { Total Section 1: }\end{array}$ & & & & \\
\hline
\end{tabular}

Please add any extra comments in the space provided on Page 4
Considerations for practice

(continued) 
IJOT

46,2

104

Teacher Section 2 (Page 3 and 4):

\begin{tabular}{|c|c|c|c|c|}
\hline $\begin{array}{l}\text { Please check the box that best describes this child } \\
\text { when compared to other children the same age }\end{array}$ & $\begin{array}{l}\text { Not like } \\
\text { this child }\end{array}$ & $\begin{array}{l}\text { Sometimes } \\
\text { like this child }\end{array}$ & $\begin{array}{l}\text { Often like } \\
\text { this child }\end{array}$ & $\begin{array}{l}\text { Always like } \\
\text { this child }\end{array}$ \\
\hline \multicolumn{5}{|l|}{ General School Skills: } \\
\hline \multicolumn{5}{|l|}{$\begin{array}{l}\text { 22. Has difficulty finding way around school or } \\
\text { unfamiliar environments }\end{array}$} \\
\hline \multicolumn{5}{|l|}{$\begin{array}{l}\text { 23. Has difficulty finding appropriate place } \\
\text { when told to stand in line or sit in circle time }\end{array}$} \\
\hline \multicolumn{5}{|l|}{ 24. Has poor ability to organise his/her desk } \\
\hline \multicolumn{5}{|l|}{ 25. Has difficulty finding items in pencil case } \\
\hline \multicolumn{5}{|l|}{ 26. Has difficulty finding specific books in bag } \\
\hline \multicolumn{5}{|l|}{ 27. Has difficulty finding correct page in book } \\
\hline \multicolumn{5}{|l|}{ 28. Skips sections when working through a page } \\
\hline \multicolumn{5}{|l|}{$\begin{array}{l}\text { 29. Shows signs of visual discomfort (e.g. } \\
\text { blinking / watering / rubbing eyes) when } \\
\text { reading or doing other close work }\end{array}$} \\
\hline \multicolumn{5}{|l|}{ Reading Skills: } \\
\hline \multicolumn{5}{|l|}{$\begin{array}{l}\text { 30. Has difficulty keeping his/her place in } \\
\text { reading (ie needs to use a finger to keep } \\
\text { place / skips a line etc) }\end{array}$} \\
\hline \multicolumn{5}{|l|}{$\begin{array}{l}\text { 31. Gets distracted when reading from a page } \\
\text { with lots of information and pictures on it }\end{array}$} \\
\hline \multicolumn{5}{|l|}{$\begin{array}{l}\text { 32. Has slow / non-fluent reading (even when } \\
\text { knows the words individually) }\end{array}$} \\
\hline \multicolumn{5}{|l|}{$\begin{array}{l}\text { 33. Has problems recognising words s/he knows } \\
\text { in different situations (e.g. in a new story) }\end{array}$} \\
\hline \multicolumn{5}{|l|}{$\begin{array}{l}\text { 34. Is reluctant to complete reading work / } \\
\text { homework compared to other tasks }\end{array}$} \\
\hline \multicolumn{5}{|l|}{ Maths Skills: } \\
\hline \multicolumn{5}{|l|}{$\begin{array}{l}\text { 35. Has difficulty lining up vertical sums } \\
\text { correctly }\end{array}$} \\
\hline \multicolumn{5}{|l|}{$\begin{array}{l}\text { 36. Tends not to use all the space available } \\
\text { when laying out sums on a page }\end{array}$} \\
\hline \multicolumn{5}{|l|}{$\begin{array}{l}\text { 37. Has difficulty reproducing numbers and } \\
\text { geometric shapes from memory }\end{array}$} \\
\hline \multicolumn{5}{|l|}{$\begin{array}{l}\text { 38. Has difficulty copying diagrams and novel } \\
\text { shapes }\end{array}$} \\
\hline $\begin{array}{l}\text { 39. Has difficulty interpreting graphs and } \\
\text { diagrams }\end{array}$ & & & & \\
\hline
\end{tabular}

(continued) 


\begin{tabular}{|c|c|c|c|c|}
\hline $\begin{array}{l}\text { Please check the box that best describes this child } \\
\text { when compared to other children the same age }\end{array}$ & $\begin{array}{l}\text { Not like } \\
\text { this child }\end{array}$ & $\begin{array}{l}\text { Sometimes } \\
\text { like this child }\end{array}$ & $\begin{array}{l}\text { Often like } \\
\text { this child }\end{array}$ & $\begin{array}{l}\text { Always like } \\
\text { this child }\end{array}$ \\
\hline \multicolumn{5}{|l|}{ Writing Skills: } \\
\hline \multicolumn{5}{|l|}{$\begin{array}{l}\text { 40. Has / had difficulty learning correct } \\
\text { placement of letters on the line i.e. which } \\
\text { letters are tall and which ones go under the } \\
\text { line }\end{array}$} \\
\hline \multicolumn{5}{|l|}{$\begin{array}{l}\text { 41. Loses his/her place resulting in errors or } \\
\text { omissions when copying from the } \\
\text { blackboard / textbook }\end{array}$} \\
\hline \multicolumn{5}{|l|}{$\begin{array}{l}\text { 42. Has to look often when copying from the } \\
\text { blackboard / textbook }\end{array}$} \\
\hline \multicolumn{5}{|l|}{$\begin{array}{l}\text { 43. Has difficulty writing the alphabet from } \\
\text { memory }\end{array}$} \\
\hline \multicolumn{5}{|l|}{$\begin{array}{l}\text { 44. Has poor judgement of spacing between } \\
\text { letters or words when writing }\end{array}$} \\
\hline \multicolumn{5}{|l|}{$\begin{array}{l}\text { 45. Tends to squash words in at the end of the } \\
\text { line }\end{array}$} \\
\hline \multicolumn{5}{|l|}{$\begin{array}{l}\text { 46. Has difficulty planning and organising use of } \\
\text { the space on a page (e.g. for a project) }\end{array}$} \\
\hline \multicolumn{5}{|l|}{ 47. Has immature drawing skills for age } \\
\hline \multicolumn{5}{|l|}{$\begin{array}{l}\text { 48. Reverses numbers and figures when writing } \\
\text { e.g. 'b' and 'd', ' and 's', ' and ' } 2 \text { ' }\end{array}$} \\
\hline \multicolumn{5}{|l|}{ 49. Size of writing varies } \\
\hline \multicolumn{5}{|l|}{$\begin{array}{l}\text { 50. Is reluctant to complete written work } \\
\text { compared to other tasks }\end{array}$} \\
\hline \multicolumn{5}{|l|}{$\begin{array}{l}\text { For Office Use Only } \\
\text { Total Section 2: }\end{array}$} \\
\hline \multicolumn{5}{|l|}{ Plus Total Sections 1: } \\
\hline \multicolumn{5}{|l|}{ Sum of Totals } \\
\hline Overall Score (Sum of all total scores): & & & & \\
\hline
\end{tabular}

Considerations for practice

Any additional information you would like to add about this child?

Parent:

Corresponding author

Charlotte Sullivan can be contacted at: charlottesullivan@eircom.net

For instructions on how to order reprints of this article, please visit our website: www.emeraldgrouppublishing.com/licensing/reprints.htm Or contact us for further details: permissions@emeraldinsight.com 